\title{
INFORMAÇÃO E CONHECIMENTO NO SETOR PÚBLICO a experiência da Fundação SEADE
}

\author{
Flavio Fava-de-Moraes \\ Maria Josefa Del Carmen Martinez Soto
}

\begin{abstract}
Resumo: Neste artigo os autores abordam a origem e o desenvolvimento da Fundação SEADE como órgão oficial responsável pela produção de dados estatísticos no Estado de São Paulo, evidenciando as condições e os desafios enfrentados pelas instituições antecessoras. Inclui, também, uma reflexão sobre os valores que norteiam a estratégia institucional.
\end{abstract}

Palavras-chave: banco de dados; estatística; indicadores; cidadania.

Abstract: This article describes the origin and development of the SEADE Foundation as an official entity charged with producing statistical data for the State of São Paulo. Attention is also given to some of the institutions that preceded SEADE, the conditions under which they operated and the challenges they faced. The authors also reflect on the institution's guiding principles.

Key words: data base; statistics; indicators, citizenship.

Onde está a vida que perdemos vivendo? Onde está a sabedoria que perdemos no conhecimento? Onde está o conhecimento que perdemos na informação?

T.S. Eliot (1934)

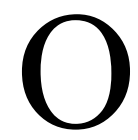
Estado de São Paulo possui, em termos efetivos, uma tradição de 110 anos dedicados à realização do objetivo de atender à demanda de informações, representada durante os últimos 24 anos pela Fundação SEADE.

No Relatório de 1898, da Repartição de Estatística e Arquivo do Estado, apresentado pelo seu então diretor, pode-se observar a descrição de algumas características do contexto em que estas instituições se desenvolveram e os desafios sempre presentes.

“ (...) mas, melhorou em qualidade pelos esforços dos proprios empregados que deram mais desenvolvimento aos dados que a Repartição conseguiu obter e apresentaram o serviço com mais detalhes.

Entretanto, o volume vai muito diminuído em numero de paginas porque abstive-me de entrar em longas analyses dos diversos mappas. Essa analyse parece-me necessaria porque é ella quem, por assim dizer, faz os algarismos fallarem ao leitor e exprimirem em linguagem commum as verdades estatísticas que encerram. Porém, a necessidade de economizar a reduzida verba concedida para o expediente e publicações desta repartição aconselhou que o presente Relatório fosse impresso nas oficinas do Diário Oficial do Estado que, com seu pequeno pessoal e grande accumulação de trabalhos, não comporta a impressão commoda e rápida de grandes volumes."

Desta síntese histórica, são facilmente compreensíveis a importância e os esforços destas instituições especializadas no acervo de dados de interesse nacional, estadual, regional e municipal que são registrados desde a segunda metade do século XIX, motivadas pela necessidade de fundamentar com dados estatísticos as necessidades humanas de conhecimento social, contribuir para o desenvolvimento de ações mais conscientes e acompanhar o impacto e as conseqüências destas ações no indivíduo e na sociedade organizada.

Já no Brasil Império houve ações oficiais com plena visão e consciência do valor cognitivo e social das estatísticas e da necessidade de criar um órgão que agregasse e desenvolvesse capacidades para reunir, organi- 
zar e publicar as informações produzidas e necessárias ao país.

O fato concreto que espelha esta decisão estratégica foi a criação da Diretoria Geral de Estatística, em 14/01/ 1871. Este setor original converteu-se no Instituto Nacional de Estatística (1934), estabelecido em 29/05/1936, e adotando, pelo Decreto-Lei ${ }^{\circ} 218$, de 26/01/1938, a sigla IBGE (Instituto Brasileiro de Geografia e Estatística). Ou seja, desde o início desta relevante missão para o Estado Brasileiro, já se vão, na prática, 131 anos de existência do "IBGE verde-amarelo", 131 anos de desenvolvimento, estruturação e disseminação das suas competências fundamentais.

Nesta história nacional, o Governo do Estado de São Paulo não se omitiu em oferecer significativa participação em face dos mesmos objetivos do IBGE, em especial, de tratar das informações de seus interesses específicos. Em março de 1892, 21 anos após a implantação do órgão nacional, foi criada, em São Paulo, a Repartição de Estatística e Arquivo do Estado, que se tornou, em 1938, Departamento Central de Estatística via Decreto no 9.036 de 14/03/1938, transformou-se em Departamento Estadual de Estatística, pelo Decreto-Lei no 9.330 e de 15/07/1938, que passou a ser denominado Departamento de Estatística do Estado de São Paulo, pela Lei no 877, de dezembro de 1950, tornando-se posteriormente Coordenadoria de Análise de Dados/Sistema Estadual de Análise de Dados Estatísticos, em dezembro de 1976, e, finalmente, Fundação Sistema Estadual de Análise de Dados - SEADE, instituída pela Lei no 1.866 , de 04/12/1978, e vinculada à Secretaria Estadual de Economia e Planejamento.

\section{A MISSÃO DA FUNDAÇÃO SEADE}

$\mathrm{O}$ âmbito de atuação e as responsabilidades técnicas e institucionais da Fundação SEADE estão expressos nas finalidades básicas estabelecidas pela Lei no 1.866 (04/ 12/78) e reiteradas no artigo $4^{\circ}$ do seu Estatuto, aprovado pelo Decreto $\mathrm{n}^{\mathrm{Q}} 13.161$ (19/01/79), a saber:

"I. coletar, organizar, analisar e divulgar informações técnicas e dados estatísticos;

II. identificar a situação do desenvolvimento econômico e social do Estado, através de levantamento e análise de dados;

III. proceder a análises conjunturais e estruturais, através da realização de estudos e pesquisas, tendo em vista o preparo de indicadores, que subsidiem a ação governamental;
IV. definir metodologias e formas de execução no âmbito da Administração centralizada e descentralizada do Estado, das atividades de identificação, obtenção, seleção e processamento de informações técnicas e dados estatísticos, para uso e divulgação pelos diversos órgãos da Administração do Estado, de acordo com os objetivos do Sistema Estadual de Análise de Dados Estatísticos SEADE;

V. acompanhar programas e projetos governamentais e informar sobre o seu andamento;

VI. divulgar, para a sociedade como um todo, informações técnicas e dados estatísticos;

VII. capacitar recursos humanos da Administração do Estado para operação e uso de informações técnicas e dados estatísticos;

VIII. realizar estudos e projetos de sua especialidade, mediante remuneração, exceto os elaborados para órgãos da Administração do Estado, quando de interesse mútuo; e

IX. desenvolver outras atividades compatíveis com as finalidades.

$\S 1^{\circ}$ - A Fundação atuará diretamente ou por intermédio de instituições públicas ou privadas mediante convênios, contratos ou concessão de auxílios.

$\S 2^{\circ}$ - Poderá a Fundação prestar serviços pertinentes a seus fins, aos Governos federal, estaduais e municipais, bem como a organizações privadas."

A reflexão sobre estas atividades revigora a compreensão do papel e das responsabilidades da Fundação SEADE na busca do equilíbrio entre a manutenção da atualidade, relevância e foco da sua produção, a integração do conhecimento, o desenvolvimento de habilidades cognitivas e organizativas e a previsão e provisão dos recursos necessários. A esta reflexão, complexa em si mesma, acrescentam-se as transformações contemporâneas da demanda e da oferta, em que conceitos, métodos de investigação, procedimentos e tecnologias estão em plena transformação, ensejando novas políticas, metas e ações no ambiente de produção de informações.

Do acima exposto, pode-se deduzir que foi proposto à Fundação SEADE uma missão abrangente e de inquestionável necessidade tanto para os poderes públicos (Executivo, Legislativo, Judiciário) como para o setor privado e a sociedade em geral, a saber: pesquisar o papel fundamental da informação e como ela é criada, identificada, coletada, processada, apresentada, acessada, gerenciada, 
preservada e como é usada ao longo do tempo em diferentes ambientes culturais e tecnológicos, além de atender a diversificados propósitos.

Cabe ainda ressaltar quais são os principais problemas e questões que se colocam no âmbito de investigação da Fundação SEADE, considerando-se a complexidade e as dimensões do Estado de São Paulo, tais como:

- constante articulação do conhecimento interativo (redes) com outras agências de produção de informação estatística, universidades, empresas, centros especializados, organizações públicas e privadas;

- entendimento e atenção às novas exigências de conhecimento da sociedade;

- capacidade de resposta às solicitações novas e às já conhecidas, atualizando e disponibilizando, na periodicidade necessária, sua fonte de dados;

- inovar continuadamente os mecanismos internos de socialização e integração dos novos conhecimentos adquiridos pelo seu quadro técnico-gerencial.

A solução destas questões é requisito para desenvolver sensibilidade quanto às necessidades de informação $\mathrm{e}$ para a manutenção da qualidade referencial da produção. Atingir tais objetivos envolve dispor de competências técnicas multidisciplinares atualizadas, bem como a capacidade de redesenhar processos de preservação, representação e utilização da informação, incorporar avanços em metodologias de investigação, em ciência da informação, em tecnologias de processamento e comunicação, constelando, assim, os fatores essencialmente estratégicos ao desenvolvimento institucional e social da Fundação SEADE.

\section{PRINCIPAIS ATIVIDADES}

Pode-se comprovar que a Fundação SEADE (e seus órgãos antecessores) vem cumprindo integralmente TODAS as atividades fins que lhe foram atribuídas (em intensidades variáveis conforme as demandas recebidas ou momentos conjunturais específicos) e contando de forma crescente com excelente credibilidade institucional em face da qualidade no desempenho de suas pesquisas.

Referência estadual e nacional na produção e disseminação de estatísticas e análises socioeconômicas e demográficas, a Fundação SEADE é também responsável pela criação de metodologias e procedimentos inovadores em cada uma das suas áreas de atuação, produzindo e organizando pesquisas primárias (próprias e de outros órgãos), captando informações setoriais (registros administrativos) e organizando e disponibilizando indicadores, tabulações e tratamentos espaciais de seus dados.

Articulando e priorizando demandas, ao longo de sua história, a Fundação SEADE faz e fez escolhas estratégicas com suas lideranças especializadas, integrando a centralidade humanística, a responsabilidade intelectual e social e os avanços tecnológicos no âmbito de suas pesquisas socioeconômicas. No âmbito nuclear de suas principais pesquisas, cabe destacar:

\section{Pesquisas Primárias (Estruturantes)}

As pesquisas específicas da Fundação SEADE caracterizam-se por complementar as de natureza nacional seja pela ausência nestes levantamentos de informações importantes sobre as complexas e dinâmicas transformações que ocorrem na realidade paulista, seja pela necessidade de aprofundamentos temáticos em questões emergentes na agenda nacional e estadual. Isto só é possível graças à presença de uma capacitação muito qualificada em todas as etapas de desenvolvimento de pesquisas de campo. Trata-se de uma estrutura única no Estado de São Paulo, apta a subsidiar rapidamente, com informações consistentes e homogêneas, as diferentes ações de políticas públicas, tanto as de natureza universal quanto as compensatórias. Alguns exemplos:

Pesquisa de Condições de Vida (PCV) - Definindo como unidade de pesquisa a família, esse levantamento classifica quadrienalmente a dinâmica e o nível de vida da população paulista, o que permite mensurar e produzir indicadores sobre carências, desigualdades sociais e condições de acesso às políticas nos temas: moradia, instrução, trabalho, renda e utilização dos serviços de saúde.

\section{Pesquisa da Atividade Econômica Paulista (Paep) -} Pesquisa qüinqüenal realizada em milhares de empresas industriais, comerciais e de serviços no Estado de São Paulo, que permite mensurar e produzir indicadores sobre inovação tecnológica, métodos gerenciais, informatização e comunicações, produtividade, terceirizações, meio ambiente, mudanças patrimoniais, requisitos para contratações, treinamento e capacitação, responsabilidade social, entre outros. O porte deste levantamento de informações gera elementos poderosos para a proposição de políticas de desenvolvimento setoriais, regionais, 
tecnológicas, de emprego e qualificação de recursos humanos.

Pesquisa Estatísticas Vitais (PEV) - Fornece informações fundamentais para a construção de projeções demográficas seguras e subsídios decisivos para o amplo planejamento de políticas públicas, em especial nas áreas de saúde e educação. A Fundação SEADE destaca-se na agilidade de obtenção e organização destas informações, aprofundando especialmente o conhecimento através de pesquisa mensal em todos os cartórios de registro civil do Estado de São Paulo, permitindo mensurar e produzir indicadores, tais como causas de morte, natalidade, fecundidade, natimortalidade, nupcialidade, migração, esperança de vida, estimativas e projeções populacionais.

Pesquisa de Emprego e Desemprego (PED) - Pesquisa mensal efetuada, desde 1984, em 3.000 domicílios na Região Metropolitana de São Paulo e, a partir de 1998, em 600 domicílios na região do Grande ABC. Seus resultados permitem um acompanhamento sistemático da dinâmica da estrutura do emprego e do mercado de trabalho. É da Fundação SEADE a coordenação metodológica da PED em outras quatro regiões metropolitanas (Porto Alegre, Belo Horizonte, Salvador e Recife) e no Distrito Federal, onde instituições locais respondem pela aplicação da pesquisa sob a supervisão local efetuada pelos escritórios regionais do Dieese.

Pesquisa Municipal Unificada (PMU) - Levantamento detalhado das características e intervenções das prefeituras dos 645 municípios do Estado de São Paulo, de execução bienal, trata da gestão das políticas e dos serviços públicos, permitindo a produção de indicadores de atuação dos municípios nas áreas de comunicação e informática, assistência social, finanças públicas, abastecimento, cultura, esporte e turismo, educação, saúde, transporte municipal, limpeza pública, saneamento básico, meio ambiente, habitação, estrutura urbana e estrutura administrativa.

Pesquisa de Investimentos - Esta pesquisa tem o propósito de identificar os anúncios de novos investimentos no Estado de São Paulo. Entre suas finalidades, destaca-se a de fornecer aos setores público e privado indicadores a respeito das tendências de expansão da atividade produtiva nos níveis regional e setorial. Capta os investimentos produtivos anunciados, ou seja, aqueles que, uma vez rea- lizados, aumentarão a capacidade produtiva da economia, passando a contribuir para o aumento da produção de bens e serviços e, conseqüentemente, para a geração de empregos em caráter permanente. Atendendo a recomendações da ONU e do próprio IBGE para o cálculo da taxa de investimento do setor privado nas contas nacionais, as empresas estatais, por oferecerem bens e serviços no mercado segundo a mesma lógica das empresas privadas, foram equiparadas a estas para efeito do levantamento dos anúncios de investimentos. A Fundação SEADE realiza a Pesquisa de Investimentos desde 1998, em parceria com a Secretaria de Estado da Ciência, Tecnologia e Desenvolvimento Econômico.

Integração de Informações Setoriais - Levantamento e organização de dados setoriais originários de instituições governamentais (federal, estaduais e municipais) e nãogovernamentais, integrados em Base de Informações, possibilitando articulação e superposição dos dados segundo diferentes agregações espaciais, aumentando assim o poder explicativo das pesquisas primárias. Setores pesquisados: administração pública; agropecuária; caracterização do território; comunicações; comércio; cultura; demografia; educação; eleições; energia; finanças públicas; indústria; investimentos; habitação; justiça e segurança; meio ambiente; previdência social; rendimento; saneamento; saúde; sistema financeiro; trabalho e transporte.

Anuário Estatístico do Estado de São Paulo - Acrescenta-se, ao capital de Bases de Dados decorrente das pesquisas e dos dados setoriais, todo o acervo de informações dos órgãos de estatística que antecederam a Fundação SEADE. Este acervo é representado, principalmente, pelo Anuário Estatístico, publicação de origem centenária, com periodicidade anual, hoje também disponível na Internet, que sistematiza as mais significativas informações demográficas, econômicas e sociais sobre a realidade paulista. Os dados são organizados por regiões administrativas e de governo e por municípios, sendo apresentados em forma de tabelas, gráficos e mapas, complementados por textos analíticos introdutórios e minuciosas notas metodológicas.

\section{Desenvolvimento de Indicadores}

Índice Paulista de Responsabilidade Social (IPRS) Indicador de terceira geração, tem como característica a sua adequação para acompanhar ações que ocorrem no 
âmbito dos 645 municípios paulistas e cuja evolução possa ser captada em períodos curtos de tempo. Essa diferenciação de desempenho do IPRS foi o que marcou o desafio demandado à Fundação SEADE pelo Fórum São Paulo - Século XXI, instituído pela Assembléia Legislativa de São Paulo. A concepção e os aspectos desta inovação foram amplamente divulgados e apresentados em diferentes fóruns no Brasil, além de discutidos e elogiados em reunião realizada entre a Fundação SEADE e o Programa do Desenvolvimento das Nações Unidas (PNUD), junto à Organização das Nações Unidas/Nova York, em 22/02/ 2001, e finalmente incorporadas no último relatório da ONU: Desenvolvimento humano: passado, presente e futuro. O IPRS foi criado pela Lei no 10.765 , de 19 de fevereiro de 2001, que outorga à Fundação SEADE, segundo o parágrafo $4^{\circ}$ do artigo $1^{\circ}$, a operação da coleta, a organização e a análise dos dados para sua elaboração.

Estimativa da Demanda da Força de Trabalho Agrícola - A metodologia atual, adaptada pela Fundação SEADE, consiste no cálculo anual da demanda da força de trabalho agrícola e consiste na definição, para cada região produtora, dos itens exigências de força de trabalho, distribuição relativa desta força de trabalho e estimativa da área cultivada no ano considerado. Estes itens permitem também a avaliação das importantes variações sazonais.

Projeções Demográficas para Pequenas Áreas - Desenvolvimento de metodologia para projeções demográficas desagregadas por municípios e distritos da capital. Esta metodologia contempla a estimativa de indicadores demográficos e seu uso no modelo de projeção por componentes. As vantagens qualitativas deste modelo, utilizado nas projeções das regiões administrativas, são também transferidas às projeções municipais e distritais.

Exploração e Análise de Registros Administrativos - A longa experiência de exploração de dados do registro civil de pessoas naturais, com finalidade de produzir indicadores demográficos, favoreceu a pesquisa de outros registros administrativos como os do INSS, visando o estudo dos acidentes fatais no trabalho. Os procedimentos metodológicos de concatenação de dados provenientes de fontes distintas (registro de óbitos e de acidentes fatais) melhoraram a cobertura dos dados e enriqueceram os resultados analíticos.

Novo Instrumento de Coleta de Dados: a Declaração de Nascido Vivo (DN) - Testada inicialmente no Estado de São Paulo por um grupo de pesquisadores da Fundação SEADE e da Secretaria de Estado da Saúde, a DN veio a ser posteriormente adotada e implantada, em todo o território nacional, pelo Ministério da Saúde.

Outras Metodologias Demográficas - Codificação, processamento e produção de indicadores de mortalidade por causas múltiplas de morte e correção das estatísticas de nascimento do registro civil com base nas informações sobre os registros atrasados de nascimentos (método RAN).

Revista São Paulo em Perspectiva - Divulgação de reflexões e análises. Publicação trimestral da Fundação SEADE, a revista é um veículo de divulgação de análises conjunturais e estruturais relativas às áreas econômica, social e política, em diversos âmbitos - do local ao internacional. Os textos divulgados são de autoria de pesquisadores da Fundação ou de outras instituições públicas e privadas, universidades e centros de pesquisa. A revista diferencia-se das demais publicações por apresentar trabalhos com características tanto teóricas quanto técnicas, agrupando, a cada número, artigos que exploram, minuciosamente, perspectivas sobre um tema específico. Sendo assim, o periódico apresenta diferentes concepções que se complementam ou até se opõem, permitindo problematizar diferentes dimensões do tema e subsidiando ações de intervenção na realidade e o desenvolvimento da pesquisa.

Já de longa tradição e com circulação nacional, a $S a ̃ o$ Paulo em Perspectiva começou a ser publicada em 1987, tendo como antecessora a Revista da Fundação SEADE, editada em 1985 e 1986. Atualmente, após aprovação em cuidadoso processo seletivo, a revista faz parte da Coleção SciELO Brasil.

\section{A MARCA SEADE}

As capacitações específicas anteriormente relacionadas, avaliadas e reconhecidas por instituições governamentais públicas (federais, estaduais e municipais) e privadas atraem demandas de desenvolvimento de projetos para o planejamento de ações em áreas estratégicas de diversos órgãos: Assembléia Legislativa de São Paulo - Fórum São Paulo Século XXI; Índice Paulista de Responsabilidade Social; Secretaria do Planejamento - Análise Regional da Economia Paulista; Secretaria de Governo e Gestão Estratégica - Oferta de Sistema de Informações; Informa- 
ções e Realizações Governamentais; Secretaria da Saúde - Informações Trimestrais sobre Nascimentos e Óbitos; Informações de Nascidos Vivos e Informações de Mortalidade; Secretaria do Emprego e Relações do Trabalho Guia de Investimentos e Geração de Empregos; Capacitação das Comissões Municipais de Emprego; Mercado de Trabalho através da Pesquisa de Emprego e Desemprego; Programa Jovem Cidadão - Meu Primeiro Trabalho; Secretaria da Cultura-Cultura e Mercado de Trabalho; Guia Cultural; Secretaria do Meio AmbientePesquisa Municipal do Meio Ambiente; Secretaria do Desenvolvimento Social - Pesquisa Municipal de Desenvolvimento Social; Secretaria da Ciência, Tecnologia, Desenvolvimento Econômico - Guia de Investimentos; Secretaria da Educação - Pesquisa Municipal de Educação; Informações Geográficas para o Planejamento Educacional; Secretaria de Administração Penitenciária - Estatísticas e Informações Criminais e Penitenciárias; Secretaria da Habitação - CDHU - Déficit, Demanda e Necessidades Habitacionais; Programa de Atuação em Cortiços; Levantamentos Cadastrais e Pesquisas Socioeconômicas; Imprensa Oficial do Estado de São Paulo Hábitos de Leitura, Acesso e Uso da Internet; Secretaria Municipal de Gestão Pública - Censo do Funcionalismo; Fundação Jorge Duprat Figueiredo de Segurança e Medicina do Trabalho - Fundacentro - Acidentes de Trabalho e Doenças Ocupacionais; Saúde e Segurança no Transporte Coletivo: Urbano, Rural e de Cargas Perigosas; Conselho Nacional dos Direitos da Mulher - Ministério da Justiça - Informações sobre a Mulher no Brasil; Fundo Nacional de Desenvolvimento da Educação - FNDE Situação Financeira e do Ensino Fundamental nos Estados e Municípios; Impactos do Fundef sobre as finanças municipais; Ministério da Educação e do Desporto - Pesquisas Nacional da Atividade Econômica Regional e do Sensor Rural; Ministério da Saúde - Metodologias Alternativas para Análise de Dados Secundários; Anuário Estatístico de Saúde do Brasil; Recuperação Histórica dos Casos de Aids; Serviço de Apoio às Micro e Pequenas Empresas de São Paulo - Sebrae/SP - Pesquisa Conjuntural da Micro e Pequena Empresa; Proposta de Regionalização; Cadastro de Entidades da Sociedade Civil; Ministério da Ciência e Tecnologia - Indicadores de Ciência e Tecnologia; Federação das Indústrias do Estado de São Paulo - Fiesp - Avaliação do Telecurso 2000; Associação Nacional de Pesquisa, Desenvolvimento e Engenharia das Empresas Inovadoras - Apei-Atividades tecnológicas em 2000; Agência Canadense - Mulheres no Mercado de Trabalho.

\section{A INFORMAÇÃO A SERVIÇO DA CIDADANIA}

Reverter para a sociedade os resultados de sua produção, dispor de meios de disseminação das informações e tornar cada vez mais universal o acesso às fontes de dados também são, ao lado da identificação da demanda e da priorização de metas de produção, aspectos fundamentais na Fundação SEADE.

Neste sentido, toda a produção da Fundação SEADE como agência pública de informações é socializada gratuitamente ao público em geral e às instituições estatais e privadas, representando informações indispensáveis para o diagnóstico da situação e das tendências dos processos demográficos, sociais e econômicos do Estado. Este valor - acesso público à informação - a Fundação SEADE estende à negociação de projetos com as instituições parceiras, garantindo assim a disponibilização dos resultados produzidos dentro de escopo específico de cada projeto.

O site SEADE (www.seade.gov.br) na Internet é o veículo que mais disponibiliza informações sobre a realidade paulista e concretiza o empenho na divulgação do acervo de dados. Embora a infoexclusão social, econômica, educacional, política e cultural ainda seja enorme, pois a Internet não chegou a $93 \%$ da população brasileira e a mais de 5.000 municípios até o ano 2000, a Fundação SEADE tem serviço de orientação ao usuário (pessoal e telefônico), atendimento on-line, e-mail (geadi@seade.gov.br), Ouvidoria e um Publishop em sua sede, ${ }^{1}$ onde no local ou por via eletrônica (www.seade.gov.br/publishop) publicações, produtos eletrônicos e a produção editorial mais recente, tanto própria como de outros 80 órgãos públicos, estão disponíveis a preços subsidiados. Importa ainda ressaltar o esforço institucional no sentido de desenvolver um ambiente propício à disseminação e ao intercâmbio do conhecimento em seus vários aspectos, através de seminários, congressos, palestras, entrevistas e artigos.

\section{A ESTRATÉGIA INSTITUCIONAL}

O projeto institucional da Fundação SEADE está ancorado basicamente em seis importantes setores, a saber: - capacitação do pessoal técnico;

- domínio do conteúdo cognitivo;

- qualidade da gestão administrativa/financeira/de projetos;

- adequada ambiência e infra-estrutura de meios;

- disponibilização dos dados produzidos e de espaços de reflexão interna e externa; 
- intercâmbio de competências com instituições similares produtoras de conhecimento.

A Fundação SEADE vem evoluindo em todos estes seis núcleos de êxitos na medida de suas possibilidades, mas, sem dúvida, reconhecendo que os seus objetivos estão prioritariamente concentrados na qualificação intelectual do seu quadro pessoal (capital humano) de pesquisadores-técnicos e funcionários, sem descuidar da sua independência e tradição institucional (capital estrutural).

Ao mesmo tempo, o sucesso nos resultados de suas atividades-fins, mesmo considerando-se a natureza versátil das mesmas, está assegurado pela reflexão e pelo domínio dos tratamentos dedicados aos dados, às informações, aos conhecimentos e às competências - elementos estruturantes do método de produção da Fundação SEADE -, definidos, caracterizados e pedagogicamente bem apresentados em recente publicação de Setzer (1999), da qual nos valemos para evidenciar alguns valores que julgamos imprescindíveis.

Os dados - processados, armazenados e comunicados - são símbolos quantificáveis e quantificados e o seu indispensável armazenamento ("banco de dados") deve ser ordenado, confiável e bem gerenciado, permitindo tratamento e assimilação segura. Só assim poderão ser convertidos em informação de utilidade pública, pelo seu usuário, pois dado não usado é estático, irrelevante e inofensivo.

Usuário é aqui entendido como o indivíduo ou profissional que, na busca de explicação dos fatos, é movido pela necessidade de entendimento das questões que se colocam para a sua capacidade cognitiva e que desenvolve novos significados e transforma o universo de dados disponível. O novo universo de significados será compartilhado institucional e socialmente à medida que as instituições e a sociedade também orientem esforços no sentido de identificar suas questões próprias, ou seja, focarem suas necessidades de conhecimento.

Quando ao dado - representado e armazenado - lhe é atribuído um significado transforma-se em informação, que será entendida e aceita (ou não), na dependência de quem confere o significado e que, sabidamente, é muito mais o seu usuário do que o seu autor. Ou seja, é uma avaliação (julgamento de valor) em que cada indivíduo, desenvolvendo seu senso crítico, adota suas interpretações, predileções, anseios e prioridades.

É o capital humano que, articulado, forma a base conceitual, o conteúdo cognitivo institucional, a precisão dos seus produtos, a responsabilidade com o contexto e o significado das explicações referenciadas pelos dados e estatísticos, bem como a viabilização de novos experimentos e aplicações.

A informação transferida, utilizada e vivenciada individualmente como uma experiência real, que causa impacto na condição cognitiva e perceptiva do indivíduo removendo ou reduzindo incertezas, transforma-se em conhecimento, que é algo pragmático, ou seja, de aplicação prática exeqüível.

A credibilidade, o reconhecimento e a confiança nas ações executadas, com base no conhecimento técnico e organizativo de uma instituição, podem ser verificados por avaliações externas especializadas, conferindo ao executor e à sua instituição a chamada competência que sempre é uma conquista complexa, versátil e própria, pois nunca será igual entre as pessoas de uma mesma equipe ou entre os quadros funcionais de órgãos similares em seus objetivos.

Admitindo-se que os dados hoje disponibilizados constituem a matéria-prima da geração de informação por quem lhes confere significados, fica inaceitável a ilusão de que somente o estoque de dados e um amplo e sofisticado acervo de equipamentos de tecnologia de informação e de rápida comunicação garantam mais exatidão nas análises, processos e produtos e, conseqüentemente, a oferta encantada de informações mais precisas para conhecimentos mais sólidos e competências inquestionáveis.

São nestes relevantes aspectos conceituais que se congregam os princípios éticos pelos quais a Fundação SEADE pauta suas ações, ciente de que, como bem público, o saber democratizado - interna e externamente - é recurso educacional estratégico como fonte de riqueza a serviço da cidadania portadora de direitos e deveres em benefício da sociedade.

\section{NOTAS}

Os autores agradecem a todo o corpo técnico-administrativo da Fundação SEADE pelas valiosas informações incorporadas neste trabalho e, em especial, à Gerência de Atendimento e Disseminação - Geadi.

1. Serviço de Orientação ao Usuário - SOU: (0XX11)3313-5777; Ouvidoria: (0XX11)3224-1721), (ouvidoria@seade.gov.br). Sede da Fundação SEADE: Av. Cásper Líbero, 464, São Paulo-SP, CEP 01033-000.

\section{REFERÊNCIAS BIBLIOGRÁFICAS}

AFONSO, C.A. Internet no Brasil: o acesso para todos é possível? Fundação Friedrich Ebert/Ildes, 2000 (Policy Paper, 26). 
"A questão da informação". São Paulo em Perspectiva. São Paulo, Fundação SEADE, v.8, n.4, 1994, p.3-8.

BARRETO, A.A. A eficiência técnica e econômica e a viabilidade de produtos e serviços de informação. Rio de Janeiro, 1996. Disponível em:

$<$ http://www.alternex.com.br/ aldoibct/avaliaao.htm $>$.

BESSON, J.-L. A ilusão das estatísticas. São Paulo, Unesp, 1995.

BRANSCOMB, A.W. Who owns information? From privacy to public access. New York, BasicBooks, 1994.

BUCCI, A.G. "A gestão do conhecimento como um dos caminhos para ajudar a organização a aprender e principalmente não esquecer”, 2002. Disponível em: <http://www.fineprint.com>.

CARVALHO, I.C.L. e KANISKI, A.L. “A sociedade do conhecimento e o acesso à informação: para que e para quem?" Ciência da Informação. Brasília, v.29, n.3, 2000, p.33-39.

CASTELLS, M. A sociedade em rede. $2^{\text {a }}$ ed. São Paulo, Paz e Terra, 1999.

CHAIA, M. "Universidade, informação e movimentos sociais". São Paulo em Perspectiva. São Paulo, Fundação SEADE, v.8, n.4, 1994, p.46-50.

CHAPARRO, F. "Conocimiento, aprendizaje y capital social como motor de desarrollo". Ciência da Informação. Brasília, v.30, n.1, 2001, p.19-31.

CHONG, N.G.S.T. "Internet technologies: towards advanced infrastructure and learning applications". In: TSCHANG, F.T. e DELLA SENTA, T. (eds.). Access to knowledge. Oxford, Pergamon Press, 2001, p.129-166.

CRETELLA JUNIOR, J. "Fronteiras do conhecimento". FMU Direito. Revista do curso de direito - UniFMU. São Paulo, v.14, n.22, 2000, p.19-40.

DOWBOR, L. Tecnologias do conhecimento: os desafios da educação. Petrópolis, Vozes, 2001 (Coleção Temas Sociais).

DUPAS, G. Ética e poder na sociedade de informação: de como a autonomia das novas tecnologias obriga a rever o mito progresso. 2a ed. São Paulo, Unesp, 2000.

FAVA-DE-MORAES, F. "Universidade, inovação e impacto socioeconômico". São Paulo em Perspectiva. São Paulo, Fundação SEADE, v.14, n.3, 2000, p.8-11.

FINQUELIEVICH, S. "Democracia eletrônica". Cooperación Sur. New York, Ano 1, 2001, p.71-93.

FORJAZ, D. A extinção do Departamento Estadual de Estatística: as opiniões dos nossos licurgos. São Paulo, 1949.

FUNDAÇÃO SEADE. "Informação: saber e mudança". São Paulo em Perspectiva. São Paulo, v.8, n.4, 1994.

GERMAN, C. "Caminhos e descaminhos políticos para a sociedade de informação". Perspectivas globais da sociedade da informação. São Paulo, Fundação Konrad Adenauer, 1997, p.31-51 (Papers, 31).

JACOBI, P. "Acesso à informação e consciência de direitos e deveres”. São Paulo em Perspectiva. São Paulo, Fundação SEADE, v.8, n.4, 1994, p.51-6.

JANNUZZI, P.M. Indicadores sociais no Brasil: conceitos, fontes de dados e aplicações. Campinas, Alínea, 2001.

JANNUZZI, P.M. e GRACIOSO, L. de S. A produção e a disseminação da informação estatística pelas agências estaduais no Brasil. Campinas, Programa de Pós-Graduação em Ciência da Informação da PUC-Campinas, 2002 (Relatório de Pesquisa).

MELO, J.M. “A muralha digital.” Revista de Cultura. Revista do Imae. São Paulo, v.2, n.2, 2001, p.49-53.
POLANCO, X. "Infometria y ingenieria del conocimiento: exploración de dados y análisis de la información en vista del descubrimiento de conocimientos". In: JARAMILLO, H. S. e ALBORNOZ, M. El universo de la medición: la perspectiva de la ciencia y la tecnología. Bogotá, Tercer Mundo, 1997.

. Aspectos da produção de informação estatística oficial no contexto da sociedade atual: algumas questões teóricometodológicas. Rio de Janeiro, Fundação IBGE, 2000 (Textos para Discussão, Diretoria de Pesquisas, 2).

PORCARO, R.M. “A informação estatística oficial na sociedade da informação: uma (des)construção”. DataGramaZero. Revista de ciência da informação, v.2, n.2, 2001. Disponível em $<$ http://www.dgz.org.br>.

RELATÓRIO da Repartição de Estatística e Archivo do Estado de São Paulo, 1898. São Paulo, Diário Official, 1900, p.1.

ROCHA, M.P.C. "A questão cidadania na sociedade da informação”. Ciência da Informação. Brasília, v.29, n.1, 2000, p.40-5.

RODRIGUES, S.B. "De fábricas a lojas de conhecimento: as universidades e a desconstrução do conhecimento sem cliente". In FLEURY, M.T.L. e OLIVEIRA JUNIOR, M.M. Gestão estratégica do conhecimento. São Paulo, Atlas, 2001, p.87-117.

SENRA, N. de C. "Por uma disseminação democrática de informações". São Paulo em Perspectiva. São Paulo, Fundação SEADE, v.8, n.4, 1994, p.40-5.

Vendo o futuro no presente: por uma agenda de estudos para o IBGE no SEM. Rio de Janeiro, ago. 2001.

Da DGE ao IBGE: 65 anos de continuidade institucional na elaboração da estatística nacional. Rio de Janeiro, 2001.

SETZER, V.W. "Dados, informação, conhecimento e competência". DataGramaZero. Revista de ciência da informação, n. 0, dez. 1999. Disponível em: <http://www.dzg.org.br>.

"Como mapear competências?" Programação. São Paulo, v.4, n.29, fev. 2001, p.13-8.

SVEIBY, K.E. Welcome to the knowledge organization. Disponível em: <http://www.sveiby.com.au>

TAKAHASHI, T. (org.). Sociedade da informação no Brasil: Livro Verde. Brasília, Ministério da Ciência e Tecnologia, 2000.

TERRA, J.C.C. Gestão do conhecimento: o grande desafio empresarial - uma abordagem baseada no aprendizado e na criatividade. São Paulo, Negócio, 2000.

THE ECONOMIST. The knowledge factory: a survey of universities. Oct . 4, 1997

UNIVERSITY OF MICHIGAN. Mission statement of the school of information. May 2001. Disponível em: $<$ http://www.si.umich.edu/about-SI/mkission.htm>.

WILKE, J. "Multimídia: novas tecnologias da comunicação mudam estruturas". Perspectivas globais da sociedade de informação. São Paulo, Fundação Konrad Adenauer, 1997, p.1-20 (Papers, 31).

Flavio Fava-de-Moraes: Diretor Executivo da Fundação Sistema Estadual de Análise de Dados, Professor Titular do Instituto de Ciências Biomédicas - USP. Foi Reitor da USP (1993-1997) e Secretário Estadual de Ciência, Tecnologia, Desenvolvimento Econômico e Turismo de São Paulo (1998).

Maria Josefa Del Carmen Martinez Soto: Assessora de Planejamento da Fundação Sistema Estadual de Análise de Dados. 